\title{
Comparison of the gonadal response of wild and laboratory field voles (Microtus agrestis) to different photoperiods
}

\author{
Norah Spears* and J. R. Clarke* \\ Department of Agricultural Science, University of Oxford, Parks Road, Oxford OX1 3PF, U.K.
}

\begin{abstract}
Summary. Weanling male and female field voles from laboratory stock and from the F1 generation of wild-caught animals were placed in a long (16L:8D) or short (6L:18D) photoperiod for 28 or 56 days. Both types of field vole showed the well-established effect of photoperiod upon sexual maturation, with animals in the long photoperiod having larger and more active gonads than animals in the short photoperiod. After 28 and 56 days laboratory stock females were more mature, sexually, and had a higher growth rate than did Wild F1 females. There was no difference between the two types of males at 28 days, but by 56 days laboratory stock males were more sexually mature and had a higher growth rate than did Wild FI males. These differences between the two types occurred in the long and short photoperiods. There was no interaction between photoperiod and type of vole. The use of laboratory stock animals in experiments could lead to an incorrect assessment of the effect of photoperiod in the control of seasonal breeding in wild populations.
\end{abstract}

\section{Introduction}

Photoperiod or daylength is an important factor controlling sexual development or seasonal breeding in the field vole (Microtus agrestis) (Baker \& Ranson, 1932, 1933). However, the gonads of field voles derived from a laboratory stock reared in short photoperiods at an ambient temperature of $20^{\circ} \mathrm{C}$ or of $2^{\circ} \mathrm{C}$ are not in such an undeveloped state as those of the majority of wild animals caught in December (Clarke \& Kennedy, 1967). As Clarke \& Kennedy suggested, this may be because several environmental factors are missing from that simple simulation of winter conditions or because after domestication over a number of generations, laboratory stock animals are no longer affected by short photoperiods in the same way as wild field voles. This, could for example, have arisen through the selection for high fertility which has been practised on the laboratory colony. Here we report the results of experiments designed to test this proposition.

\section{Materials and Methods}

Progeny from two sources of field voles were used. Source 1 was the main breeding colony maintained in the Department of Agricultural Science, Oxford University, and founded in 1958 with animals from Wytham Biological Reserve, Oxfordshire. The husbandry of this colony is described by Baker \& Clarke (1986). Animals from this source are referred to as laboratory stock.

Source 2 was male and female voles, live-trapped in Wytham Biological Reserve in October 1983, and paired in the laboratory to form a subsidiary breeding colony, kept in the same conditions of husbandry as the established colony. Animals from this source are referred to as Wild F1.

*Present address: Department of Zoology, University of Oxford, South Parks Road, Oxford OX1 3PS, U.K. 
Both colonies were kept in a photoperiod of $16 \mathrm{~h}$ light:8 $\mathrm{h}$ dark $(16 \mathrm{~L}: 8 \mathrm{D})$ at $18-20^{\circ} \mathrm{C}$, lights on at $08: 00 \mathrm{~h}$.

The experiment was designed as a $2 \times 2$ factorial (Bailey, 1981), the two factors being 'type of animal' (laboratory stock; Wild F1) and photoperiod (long photoperiod; short photoperiod: see below). Animals were weaned at the age of $16 \pm 1$ days, and placed in cages within photoperiod cabinets (Grocock \& Clarke, 1974) providing lighting regimens of $16 \mathrm{~L}: 8 \mathrm{D}$ or $6 \mathrm{~L}: 18 \mathrm{D}$ at $18-20^{\circ} \mathrm{C}$. In both lighting regimens, lights went on at 10:00 $\mathrm{h}$. Each cabinet was fitted with four $25 \mathrm{~W}$ tungsten bulbs, giving a light intensity of $188.3 \mathrm{klx}$ at the front of the cage and $27.2 \mathrm{klx}$ in the nest. These cabinets were kept in a room separate from the breeding colonies.

Allocation of animals to the treatments was as follows: two Wild FI field voles were matched with two laboratory stock field voles, of the same sex and age and of a similar body weight $(8-12 \mathrm{~g})$ and state of sexual immaturity. Within such a block of 4 animals, one Wild F1 and one laboratory stock field vole, selected at random from each pair, were placed in long photoperiod and the other two in short photoperiod. For both males and females there were 6 blocks of 4 animals treated for 28 days and the same number for 56 days. They were fed whole oats and Dixon's diet 41B ad libitum, supplemented twice weekly with carrots and hay. Water was constantly available. At the end of the treatments, animals were killed with ether vapour. Ovaries, uteri and testes were weighed fresh and fixed in Bouin's fluid. Carcasses of males were preserved in $10 \%$ formalin, and the seminal vesicles were later weighed. Ovaries and testes were embedded in parafin wax. Serial sections of ovaries, and sections of testes (both cut at $6 \mu \mathrm{m}$ ) were stained in Ehrlich's haematoxylin and eosin. Using the follicle classification of Pedersen \& Peters (1968), total numbers of follicles of types 6,7 and 8 were counted in pairs of ovaries. All atretic follicles (defined as follicles containing 5 or more pycnotic nuclei in the granulosa) were also counted. Width of seminiferous tubules was obtained by measuring 15 tubules in each animal, and using the mean of these figures in the statistical analysis. Testes were also scored for spermatogenic index by the system of Grocock \& Clarke (1974) in which testes are rated from 0 to 5 , according to the activity of the seminiferous epithelium, where ' 0 ' represents the presence of Sertoli cells, spermatogonia and a few primary spermatocytes and ' 5 ' represents complete spermatogenesis with abundant spermatozoa.

Growth rates were calculated from the difference between final and initial body weights divided by time in days.

The significance of effects of treatments was tested by a Factorial Analysis of Variance (Bailey, 1981).

\section{Results}

\section{Females}

Uterine weights. There was a significant photoperiod and type effect on uterine weight after both 28 and 56 days of treatment ( $P<0.01$ in all cases) (Table 1), with females in the long photoperiod having heavier uteri than females in the short photoperiod, and with laboratory stock females having heavier uteri than Wild F1 females. However, there was no interaction between type and photoperiod. There was no significant difference between uterine weights at 28 and 56 days.

Ovaries. There was a significant photoperiod effect on ovarian weight at both 28 and 56 days ( $P<0.05$ and $P<0.01$ respectively), with animals in the long photoperiod having heavier ovaries than those in the short photoperiod, but there was no type effect (Table 1). There were no corpora lutea in any of the ovaries.

After 28 days of treatment, there was no light, type or interactive effect on ovarian follicle numbers. By 56 days of treatment (Table 2), there were significantly more follicles of types 7 and 8 and significantly more atretic follicles in the ovaries of females in the long photoperiod than in those in the short photoperiod $(P<0.05, P<0.05$ and $P<0.01$, respectively), but no type or interactive effect.

\section{Males}

Testicular weights. After both 28 and 56 days, the long-photoperiod animals had significantly heavier testes than did those from the short photoperiods $(P<0.001$ in both cases) but there was no type or interactive effect after 28 or 56 days (Table 3). However, by 56 days testes of 2 of the 6 laboratory stock animals in the short photoperiod had enlarged considerably, weight 200 and $259 \mathrm{mg}$; the testes of the other 4 males weighed $47.0 \pm 10.2 \mathrm{mg}$, compared with $29.7 \pm 6.0 \mathrm{mg}$ for the 6 Wild F1 animals in the short photoperiod.

Seminal vesicle weights. Seminal vesicles were significantly heavier in field voles from long photoperiods than in those from short photoperiods at 28 and 56 days $(P<0.05$ and $P<0.001$ respectively). There was a significant type effect on seminal vesicle weight at 56 days only, those from 
Table 1. Uterine and ovarian weights ( $\mathrm{mg}$ ) of laboratory stock and Wild Fl female field voles, placed in a long (LP) or short (SP) photoperiod for 28 or 56 days

\begin{tabular}{|c|c|c|c|c|c|c|c|}
\hline & \multicolumn{4}{|c|}{ Treatment } & \multirow{3}{*}{$\begin{array}{l}\text { Photoperiod } \\
\text { effect }\end{array}$} & \multirow{3}{*}{$\begin{array}{l}\text { Type } \\
\text { effect }\end{array}$} & \multirow{3}{*}{$\begin{array}{c}\text { Interaction } \\
\text { effect }\end{array}$} \\
\hline & \multicolumn{2}{|c|}{ Laboratory stock } & \multicolumn{2}{|c|}{ Wild F1 } & & & \\
\hline & LP & SP & LP & SP & & & \\
\hline \multicolumn{8}{|c|}{ Uterine weights } \\
\hline 28 days & $45 \cdot 0 \pm 6 \cdot 3$ & $18.8 \pm 7.8$ & $15 \cdot 5 \pm 3 \cdot 5$ & $6 \cdot 0 \pm 0 \cdot 6$ & $P<0.01$ & $P<0.01$ & n.s. \\
\hline 56 days & $41 \cdot 1 \pm 8 \cdot 6$ & $15.9 \pm 3.7$ & $19 \cdot 9 \pm 4.7$ & $6.0 \pm 0.9$ & $P<0.01$ & $P<0.01$ & n.s. \\
\hline \multicolumn{8}{|c|}{ Ovarian weights } \\
\hline 28 days & $4.5 \pm 0.5$ & $3.2 \pm 0.4$ & $3.9 \pm 0.3$ & $3.3 \pm 0.4$ & $P<0.05$ & n.s. & n.s. \\
\hline 56 days & $4.3 \pm 0.5$ & $2 \cdot 6 \pm 0.2$ & $4.3 \pm 0.7$ & $2.5 \pm 0.4$ & $P<0.01$ & n.s. & n.s. \\
\hline
\end{tabular}

Values are mean \pm s.e.m.; 6 animals per treatment. n.s., not significant.

Table 2. Numbers of Graafian follicles, types 6, 7 and 8, and of atretic follicles in ovaries of laboratory stock and Wild F1 female field voles, placed in a long (LP) or short (SP) photoperiod for 56 days

\begin{tabular}{|c|c|c|c|c|c|c|c|}
\hline \multirow[b]{3}{*}{ Follicles } & \multicolumn{4}{|c|}{ Treatment } & \multirow{3}{*}{$\begin{array}{c}\text { Photoperiod } \\
\text { effect }\end{array}$} & \multirow{3}{*}{$\begin{array}{l}\text { Type } \\
\text { effect }\end{array}$} & \multirow{3}{*}{$\begin{array}{l}\text { Interaction } \\
\text { effect }\end{array}$} \\
\hline & \multicolumn{2}{|c|}{ Laboratory stock } & \multicolumn{2}{|c|}{ Wild F1 } & & & \\
\hline & LP & $\mathrm{SP}$ & LP & SP & & & \\
\hline Type 6 & $2 \cdot 5 \pm 1 \cdot 0$ & $2.8 \pm 0.8$ & $3.2 \pm 0.8$ & $2.5 \pm 0.6$ & n.s. & n.s. & n.s. \\
\hline Type 7 & $2.8 \pm 0.7$ & $1.3 \pm 0.2$ & $2.5 \pm 0.6$ & $1.7 \pm 0.5$ & $P<0.05$ & n.s. & n.s. \\
\hline Type 8 & $2.2 \pm 0.6$ & $0.5 \pm 0.3$ & $1.7 \pm 0.6$ & $0.7 \pm 0.3$ & $P<0.05$ & n.s. & n.s. \\
\hline Atretic & $5 \cdot 5 \pm 1 \cdot 0$ & $2.7 \pm 0.8$ & $6.0 \pm 0.8$ & $3.3 \pm 0.6$ & $P<0.01$ & n.s. & n.s. \\
\hline
\end{tabular}

Values are mean \pm s.e.m.; 6 animals per treatment. n.s., not significant.

Table 3. Testicular and seminal vesicle weights $(\mathrm{mg})$, seminiferous tubule width $(\mu \mathrm{m})$ and spermatogenic index of laboratory stock and Wild F1 male field voles, placed in a long (LP) or short (SP) photoperiod for 28 or 56 days

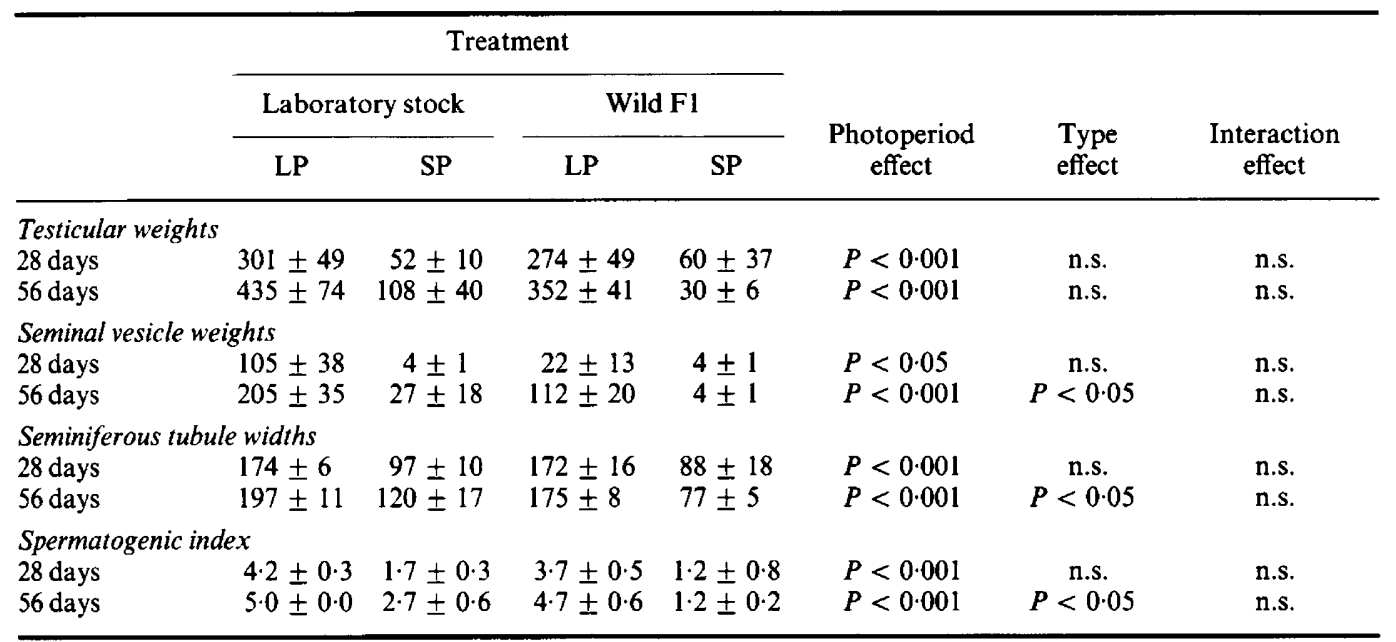

Values are mean \pm s.e.m.; 6 animals per treatment. n.s., not significant. 
laboratory stock animals being heavier than those from Wild F1 animals $(P<0.05)$, but there was no interactive effect (Table 3 ).

Seminiferous tubule width and spermatogenic index. At 28 and 56 days there was a photoperiod effect on seminiferous tubule width $(P<0.001)$, which was greater in the long than in the short photoperiod (Table 3$)$. By 56 days there was also a type effect $(P<0.05)$, with laboratory stock males having wider seminiferous tubules than did Wild F1 males. Similarly, there was a photoperiodic effect on the spermatogenic index at 28 and 56 days $(P<0.001$ for both) and a type effect at 56 days $(P<0.05)$, males in the long photoperiod having a higher rating than those in the short, and laboratory stock males having a higher rating than Wild F1 males. There was no interactive effect at 28 or 56 days (Table 3 ).

\section{Growth rates}

Growth rates were not significantly affected by photoperiod (Table 4 ). There was, however, a type effect for females at 28 days $(P<0.05)$ and for females and males at 56 days $(P<0.01$ and $P<0.05$ respectively), with the growth rates of the laboratory stock voles being greater than those of the Wild F1 voles. There was no interaction between type and photoperiod.

Table 4. Growth rates (g/day) of laboratory stock and Wild $\mathrm{F} 1$ female and male field voles, placed in a long (LP) or short (SP) photoperiod for 28 or 56 days

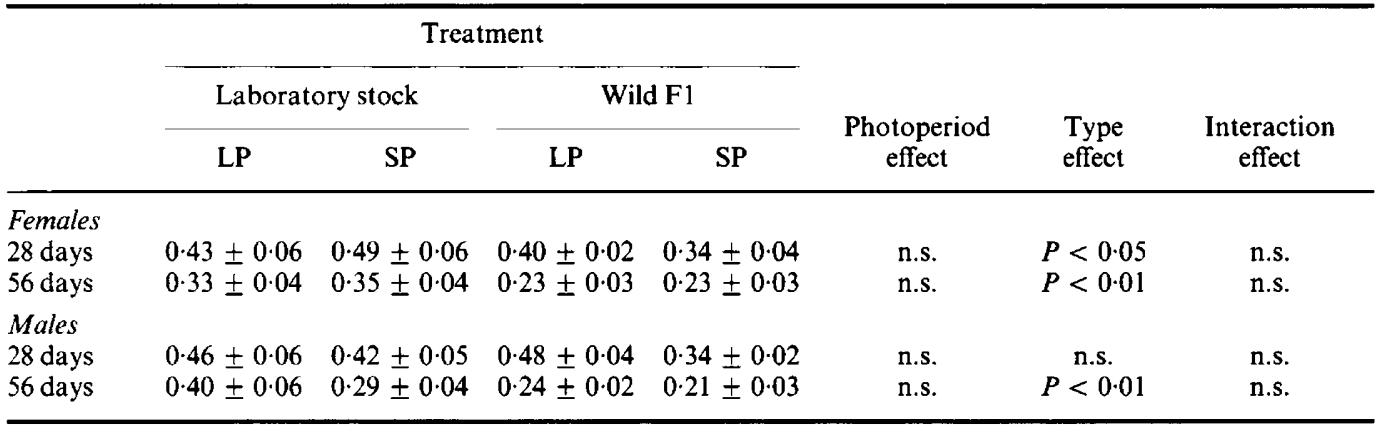

Values are mean \pm s.e.m.; 6 animals per treatment. n.s., not significant.

\section{Discussion}

Young female and male field voles, from the laboratory stock and from the colony of wild animals, showed the well-established effect of photoperiod upon sexual maturation (Baker \& Ranson, 1932; Clarke \& Kennedy, 1967; Grocock \& Clarke, 1974), with animals in the long photoperiod being more mature than those in the short photoperiod. However, the size of the response in both the long and the short photoperiod was influenced by the type or source of field vole.

Judged by uterine and ovarian weights, there was no change in female sexual development between 28 and 56 days. At both of these times the effect of type upon the sexual maturation was apparent from uterine weights, which is known, from work on mice and rats, to be a considerably more sensitive measure of total gonadotrophin secretion than is the weight of the ovaries (Loraine \& Bell, 1966). Wild F1 females were significantly less sexually developed than laboratory stock females in long and short photoperiods. Indeed, there was no significant difference between Wild Fl females in the long photoperiod and laboratory stock females in the short photoperiod. The lack of any interaction between type and photoperiod shows that, while the laboratory stock females mature sexually at a faster rate than do the Wild F1 females, the sexual development of 
laboratory stock females is retarded relatively to the same extent by short photoperiod as is that of the Wild Fl animals. There was no type effect on ovarian weight or on the number of different types of antral or atretic follicles. The greater number of antral follicles of types 7 and 8 in females from the long compared with those from the short photoperiod is presumably a reflection of greater gonadotrophin release. Follicular atresia is increased by hypophysectomy and reduced by gonadotrophins (Tsafriri \& Braw, 1984), and so the larger number of atretic antral follicles in females from the long photoperiod may be a reflection of the greater number of antral follicles available to undergo atresia. As the field vole is an induced ovulator (Breed, 1967), the absence of corpora lutea in the ovaries is to be expected.

As suggested by testicular weights and shown by seminal vesicle weights, both types of male continued to develop sexually between 28 and 56 days of treatment. No effect of type upon male response to photoperiod was apparent until 56 days. Although testicular weight showed no significant type effect, seminiferous tubule width, the state of the seminiferous epithelium and seminal vesicle weight all showed that after 56 days, in the long and short photoperiods, laboratory stock animals were more advanced in their sexual development than were Wild FI animals. There are indications in the results that laboratory stock males would be more fertile than Wild F1 males. At 56 days, laboratory stock animals had significantly larger seminal vesicles than did Wild F1 animals. This may be because the laboratory stock males released androgens earlier or in larger amounts than did the Wild F1 males, or because they were more sensitive to the effects of androgens. Such differences might be associated with differences in sexual motivation. Furthermore, the size and contents of the seminiferous tubules also suggested greater fertility in the laboratory stock males. In both types, spermatogenesis was complete in the testes of the long-photoperiod males, but seminiferous tubules were wider and spermatozoa were more abundant in laboratory stock than in Wild F1 males. In the short photoperiod, laboratory stock males had wider seminiferous tubules than did Wild F1 males, and the germ cells of the seminiferous tubules in laboratory stock males comprised all types up to and including round and elongated spermatids, whereas in the Wild F1 males there were for the most part only spermatogonia, some primary spermatocytes and, in a few animals, a very small number of round spermatids.

Although laboratory stock males are more developed sexually than Wild F1 males at 56 days, the absence of an interaction between type and photoperiod shows that, as with the females, laboratory stock males are still as affected by the short photoperiod, relative to their sexual development in long photoperiod, as are Wild Fl males.

Growth rate was affected by type of field vole, but not by photoperiod. Laboratory stock voles grew at a faster rate in the long and short photoperiods than did Wild F1 voles. This was apparent after 28 and 56 days in females, but only after 56 days in males. The absence of a photoperiod effect on growth rate is puzzling, as Spears \& Clarke (1986) found that female field voles grew at a faster rate in long than in short photoperiods. There seems to be no consistent relationship between photoperiod and growth rate amongst other species. Short photoperiods decrease the body weight of male meadow voles (Microtus pennsylvanicus) (Dark \& Zucker, 1984), and the growth rate of female house mice is depressed by constant light (Drickamer, 1975). On the other hand, growth of the prairie vole (Microtus ochrogaster) and the Australian bush rat (Rattus fuscipes) is unaffected by photoperiod (Wunder, 1984; Irby et al., 1984).

Clarke (1977), comparing the response to photoperiod of Wild F1 and laboratory stock field voles in 1971, briefly reported differences similar to those reported here. The Wild F1 field voles studied by Clarke (1977) came from the same habitat as the wild animals used in the present experiment. The similarity of the results in 1971 and those presented here suggests that, although there was an initial selection in the laboratory colony for faster maturing and faster growing field voles, this selection seems to have occurred early in the history of the colony, after which the rate of sexual maturation has remained fairly constant. The fact that the sexual development of the Wild Fl animals in both investigations was essentially the same makes it unlikely that the founding wild animals of the subsidiary wild colonies were unrepresentative. 
In establishing and maintaining a breeding colony derived from wild animals, the artificial selection for fertility practised from the outset may carry with it some independence of sexual development from the effect of environmental conditions. The experiments described here show that, in this colony of field voles, photoperiod has an effect on the sexual maturation of the voles, such that maturation is inhibited by short photoperiods. However, the response of the voles to both long and short photoperiods is substantially different from that of the Wild F1 animals. Laboratory stock animals were shown to grow and mature sexually at a faster rate than Wild Fl voles in both long and short photoperiods. This contrasts with laboratory stock from a breeding colony of prairie voles (Microtus ochrogaster) which, 12 years after the creation of the colony, showed no inhibition of male sexual development in a short photoperiod, unlike the Wild F1 prairie voles (Nelson, 1985). However, the inhibition in Wild F1 prairie voles by short photoperiods is not nearly as marked as in the Wild F1 field voles seen here. Domestication of house mice has also been shown to change the response of their reproductive system to artificial light: high light intensities reduced the fertility of Wild F1 but not of laboratory stock house mice (Bronson, 1979). The reproductive characteristics of laboratory bred animals can also be influenced by the geographical origin of wild mammals used to found laboratory breeding colonies (Drickamer \& Vestal, 1973; Innes, 1978; Gustafsson et al., 1983). Likewise, there are differences in the length of breeding season and in the seasonal pattern of hormone secretion between breeds of sheep which have been attributed to the different environments in which the breeds arose (D'Occhio et al., 1984; Haresign \& McLeod, 1985).

The present results are important in two ways. Firstly, if field voles, or any other comparable species, from a well-established laboratory breeding colony are used to test the effect of an environmental factor on the sexual maturation of the animals, the results could wrongly estimate the effect of that factor in the wild. Secondly, the occurrence of genetic factors influencing the fertility of a species of microtine rodent, attributable perhaps to altered response to gonadotrophins (Bindon \& Pennycuik, 1974) and brought about through changes in receptor numbers (Tähkä \& Rajaniemi, 1985), could contribute to the occurrence of microtine population cycles (Krebs \& Myers, 1974).

N.S. was supported by a Natural Environmental Research Council Research Studentship. We thank Janet Evans and Valerie Petts for invaluable assistance with this work.

\section{References}

Bailey, N.T.J. (1981) Statistical Methods in Biology. Hodder \& Stoughton, London.

Baker, J.B. \& Clarke, J.R. (1986) The field vole (Microtus agrestis) and the bank vole (Clethrionomys glareolus). In UFAW Handbook on the Care and Management of Laboratory Animals. Ed. T. B. Poole. Longman, London (in press).

Baker, J.R. \& Ranson, R.M. (1932) Factors affecting the breeding season of the field mouse (Microtus agrestis). Part I. Light. Proc. R. Soc. B. 110, 313-322.

Baker, J.R. \& Ranson, R.M. (1933) Factors affecting the breeding season of the field mouse (Microtus agrestis). Part III. Locality. Proc. R. Soc. B 113, 486-495.

Bindon, B.M. \& Pennycuik, P.R. (1974) Differences in sensitivity of mice selected for fecundity. J. Reprod. Fert. 36, 221-224.

Breed, W.G. (1967) Ovulation in the genus Microtus. Nature, Lond. 214, 826.

Bronson, F.H. (1979) Light intensity and reproduction in wild and domestic house mice. Biol. Reprod. 21, 235-239.

Clarke, J.R. (1977) Long and short term changes in gonadal activity of field voles and bank voles. Oikos 29, 457-467.

Clarke, J.R. \& Kennedy, J.P. (1967) Effect of light and temperature upon gonadal activity in the vole (Microtus agrestis). Gen. comp. Endocr. 8, 474-488.

Dark, J. \& Zucker, I. (1984) Gonadal and photoperiodic control of seasonal body weight changes in male voles. Am. J. Physiol. 247, 84-88.

D'Occhio, M.J., Schanbacher, B.D. \& Kinder, J.E. (1984) Profiles of LH, FSH, testosterone and prolactin in rams of diverse breeds: effects of contrasting short (8L:16D) and long (16L:8D) photoperiods. Biol. Reprod. 30, 1039-1054.

Drickamer, L.C. (1975) Female mouse maturation: relative importance of social factors and daylength. $J$. Reprod. Fert. 44, 147-150.

Drickamer, L.C. \& Vestal, B.M. (1973) Patterns of repro- 
duction in a laboratory colony of Peromyscus. $J$. Mammal. 54, 523-528.

Grocock, C.A. \& Clarke J.R. (1974) Photoperiodic control of testis activity in the vole, Microtus agrestis. $J$. Reprod. Fert. 39, 337-347.

Gustafsson, T.O., Andersson, C.B. \& Westlin, L.M. (1983) Reproduction in laboratory colonies of bank vole, Clethrionomys glareolus, originating from populations with different degrees of cyclicity. Oikos $\mathbf{4 0}$, $182-188$.

Haresign, W. \& McLeod, B.J. (1985) Physiological criteria in genetic selection for aseasonality. In Genetics of Reproduction in Sheep, pp. 291-300. Ed. R. B. Land \& D. W. Robinson, Butterworths, London.

Innes, D.G.L. (1978) A reexamination of litter size in some North American microtines. Can. J. Zool. 56, 1488-1496.

Irby, D.C., Kerr, J.B., Risbridger, G.P. \& de Kretser, D.M. (1984) Seasonally and experimentally induced changes in testicular function of the Australian bush rat (Rattus fuscipes). J. Reprod. Fert. 70, 657-666.

Krebs, C.J. \& Myers, J.H. (1974) Population cycles in small mammals. Adv. ecol. Res. 8, 267-399.

Loraine, J.A. \& Bell, E.T. (1966) Hormone Assays and their Clinical Application. Livingstone, Edinburgh.
Nelson, R.J. (1985) Photoperiodic regulation of reproductive development in male prairie voles; influence of laboratory breeding. Biol. Reprod. 33, 418-422.

Pedersen, T. \& Peters, H. (1968) Proposal for a classification of oocytes and follicles in the mouse ovary. $J$. Reprod. Fert. 17, 555-557.

Spears, N. \& Clarke, J.R. (1986) Effect of male presence and of photoperiod on the sexual maturation of the field vole (Microtus agrestis). J. Reprod. Fert. 78, 231-238.

Tähkä, K.M. \& Rajaniemi, H. (1985) Photoperiodic modulation of testicular LH receptors in the bank vole (Clethrionomys glareolus). J. Reprod. Fert. 75, 513-519.

Tsafriri, A. \& Braw, R. (1984) Experimental approaches to atresia in mammals. In Oxford Reviews of Reproductive Biology, Vol. 6, pp. 226-265. Ed. J. R. Clarke, Clarendon Press, Oxford.

Wunder, B.A. (1984) Strategies for, and environmental cueing mechanisms of, seasonal changes in thermoregulatory parameters of small mammals. In Winter Ecology of Small Mammals, pp. 165-172. Ed. J. F. Merritt. Special publication of Carnegie Museum of Natural History, No. 10.

Received 21 April 1986 